\title{
Acervos fotográficos públicos: uma introdução sobre digitalização no contexto político da disseminação de conteúdos
}

\author{
Rubens Silva \\ Doutor em ciência da informação (UFRJ/lbict, 2002). \\ E-mail: rubensri@ufba.br
}

\section{INTRODUÇÃO}

Um amplo estudo cuja metodologia caracterizou-se pela abordagem dialética e pelo enfoque epistemológico permitiu-nos, em passado recente, investigar reflexos sociais e institucionais da adoção de tecnologias de conversão digital de acervos fotográficos públicos, apontando para a possibilidade de expansão da consciência e, assim, da capacidade de conhecer e agir, mediante fruição de imagens fotográficas. No estudo, foram também investigados aspectos técnicos e novas metodologias de trabalho adotadas, demandas de consulentes e também limitações e necessidades institucionais no contexto de um "universo digital", fórum privilegiado onde os diversos campos da representação e da produção humana apresentam-se interligados. ${ }^{*}$

Evidenciaremos, neste artigo, alguns elementos que possam contribuir para a reflexão e o debate acerca da digitalização de acervos fotográficos públicos para acesso remoto e de sua relevante aplicabilidade na tessitura social, no sentido da preservação da memória visual, do fortalecimento da identidade e do acesso a um conteúdo informacional pleno de elementos para a ampliação do conhecimento em todos os âmbitos de formação educacional e cultural. Complementarmente, abordaremos conceitos associados ao contexto da elaboração de políticas de disseminação de conteúdos informacionais digitais.

\footnotetext{
* Originalmente a pesquisa foi realizada na cidade do Rio de Janeiro, com o apoio da Coordenação de Aperfeiçoamento de Pessoal de Nível Superior (Capes) (cf. Silva, 2002; v.tb. Silva, 2003). A temática da investigação, no entanto, continua sendo desenvolvida, atualmente, em âmbito local, na cidade do Salvador, por meio do plano de trabalho Coleções especiais de instituições públicas federais em Salvador: que reflexos sociais e institucionais a digitalização pode promover?, desenvolvido pela graduanda em arquivologia Lívia Ferreira Tosta. Esse plano de trabalho foi contemplado com uma bolsa (2005-2006) da Fundação de Apoio à Pesquisa no Estado da Bahia, no âmbito do Programa Institucional de Bolsas de Iniciação Científica (Pibic/Fapesb), e foi elaborado como parte integrante do projeto de pesquisa A conversão digital de documentos especiais de acervos públicos como instrumento de desenvolvimento da consciência informacional: aspectos técnicos e teóricos no âmbito da ciência da informação, proposto por este autor.
} 


\section{A REPRODUTIBILIDADE DIGITAL DOS ACERVOS FOTOGRÁFICOS}

A disseminação de conteúdo digital via redes de comunicação vem trazendo em seu bojo mudanças de procedimentos institucionais e pessoais no relacionamento com outras formas de cultura e erudição. Imagens fotográficas, por exemplo, proliferam-se indefinidamente por meio de suas representações digitais.

Pioneiro, Walter Benjamin já havia enfatizado a grande capacidade que a reprodução técnica oferece em termos de preservação, em se tratando da arte. Em contrapartida, chamou a atenção para a necessidade de uma alternativa para a transmissão da memória, que assegurasse sua disseminação no futuro não apenas como uma forma de representação, mas como experiência; não apenas como exibição de trabalhos artísticos, mas como uma forma de se estabelecer outra relação entre tempo e memória. Em importante artigo de 1936, intitulado "A obra de arte na era de sua reprodutibilidade técnica”, Benjamin refletiu sobre o problema da subversão que a multiplicação das técnicas de reprodução introduz na arte, provocando profunda modificação na qual reproduções passam a se impor de forma tal que chegam a tornar-se, elas próprias, formas originais de arte. A obra de arte então reproduzida perde sua aura, sua possibilidade de aparição única. A arte contemporânea seria tanto mais eficaz quanto mais se orientasse em função da reprodutibilidade, quanto menos colocasse em seu centro a obra original. Benjamin nos lembra que:

No interior de grandes períodos históricos, a forma de percepção das coletividades humanas se transforma ao mesmo tempo que seu modo de existência. $\bigcirc$ modo pelo qual se organiza a percepção humana, o meio em que ela se dá, não é apenas condicionado naturalmente, mas também historicamente (...) Fazer as coisas "ficarem mais próximas" é uma preocupação tão apaixonada das massas modernas como sua tendência a superar o caráter único de todos os fatos através de sua reprodutibilidade. Cada dia fica mais irresistível a necessidade de possuir o objeto, de tão perto quanto possível, na imagem, ou antes, na sua cópia, na sua reprodução (BENJAMIN, 1986, p.169-170).

O "ser de uma imagem", para utilizarmos uma expressão de Lévy, não existe intrinsecamente, sendo determinado em função do uso que se faz da imagem, das interpretações e dos sentidos dados à imagem sucessiva e simultaneamente por múltiplas coalizões sociais:
Não são portanto a objetivação, a conexão mecânica entre a causa e o efeito, ou o desdobramento cego de um "sistema técnico" pretensamente inumano que melhor qualificam a técnica, mas sim a formigante atividade hermenêutica de inúmeros coletivos (LEVY, 1993, p.188).

Ao operar-se uma transposição desta formulação para a categoria dos acervos fotográficos públicos, levando-se em consideração as possibilidades oferecidas pela tecnologia, a eficácia institucional passaria a estar associada à disponibilização digital remota de seus acervos para amplo segmento da sociedade, maximizando sua utilização e satisfazendo as necessidades e demandas da sociedade em uma era de conteúdos informacionais "binários", além de possibilitar um reconhecimento da própria sociedade na qual vivemos. Silva (2000), ao estudar questões relativas à recuperação de representações imagéticas e às distinções entre o que chamou de informação estética e informação semântica, já destacou a importância da visão e da visualidade e, portanto, da fruição, como recurso perceptivo e processo cognitivo de que dispõe o ser humano no aprendizado e no desenvolvimento de seu conhecimento acerca do mundo. Da mesma forma, Hollanda já observou, ao pesquisar a fotografia documental urbana, que o conteúdo de imagens fotográficas propicia ao indivíduo um "potencial de dados que, no caso da cidade, ajuda a traçar um reconhecimento na representação urbana, pela dimensão da novidade contida no registro da imagem" (HOLLANDA, 2000, p.177).

Por participar de tal forma na vida cotidiana, a fotografia acaba por exprimir desejos e necessidades de camadas sociais as mais diversas, não podendo, de fato, ser entendida apenas como mais um processo de criação, já que é, sobretudo, um dos mais eficazes meios de influência em nosso comportamento e até no desenvolvimento de nossas idéias. Se colecionamos fotografias, sentimos algo como viver momentos vividos por um outro, com ele, adotando-os. E, diante de uma fotografia, conforme sugere Lemagny (1992, p.94), "não dizer apenas: 'isto foi', mas 'nisto, também eu fui””. Mesmo quando já inserida na coleção de algum museu, com circulação mais restrita e, portanto, tendo reduzido sua possibilidade de ser questionada, a fotografia torna-se, então, 'questionante' em seu próprio silêncio:

Cessamos de perguntar-lhe: "O que você representa, o que você quer dizer?"; é ela que passa a questionar: "O que você sabe sobre o que você vê aqui? $\mathrm{O}$ que você pode dizer sobre isto?" (LEMAGNY, 1986, p.5). 
Soulages atenta para a inadequação, o reducionismo, o erro, de se entender uma foto como o registro de uma essência. Seria uma impostura com a fotografia, a linguagem, o real e a com a própria essência:

Ver uma foto é articular três visões: a da singularidade, a da fotograficidade e a do símbolo. É a dialética entre estas três visões que faz a riqueza de um olhar dirigido e detido sobre uma foto. Esta dialética trabalha a especificidade da fotografia. Ela permite [também] uma ... visão crítica ... destino que habita toda arte e que the confere valor, melhor dizendo, torna impossível sua substituição (SOULAGE, 1986, p.38, grifos no original).

Contemplando uma fotografia, em um primeiro momento é o silêncio que parece nos interrogar, permitindo-nos maior atenção ao que estamos fazendo ou olhando. Haertel (1990) tece considerações acerca da percepção humana, reportando-se à noção de silêncio. Quando prestamos atenção em algo, uma atenuação da consciência de todas as outras percepções sensoriais se processa. No entanto,

à medida que voltamos a fixar o nosso olhar no mesmo objeto, outras inferências perceptivas, advindas da memória de nossos outros sentidos, podem transformar, significativamente, a impressão daquilo que vemos.

Este mecanismo perceptivo pode transformar "a experiência visual de uma recepção passiva, retiniana, em uma recepção enriquecida, instigante", na qual se questiona o que se vê, com um olhar contemplativo às coisas tais como são, como se as estivéssemos vendo pela primeira vez, um

olhar criativo... oposto de um olhar fugaz e rápido, que toma por já visto aquilo que acaba de olhar ou aceita velhas ou usadas interpretações daquilo que é visto (HAERTEl, 1990, p.57).

A fotografia realiza seu papel cognoscitivo a partir do momento em que é "capaz de perfurar as máscaras, aquilo que se apresenta imediatamente à experiência, e propor olhares não familiares sobre o mundo", e com a condição de que se reconheça que "o sentido das fotos nunca está completo nelas mesmas, mas que se constitui e varia no processo de circulação social" (CANCLINI, 1987, p.1618). É o processo de circulação social, variado, subjetivo, culturalmente específico, que preenche de sentido uma fotografia, a partir do grau de atração e provocação que exercerá sobre cada um de nós: "a onipresença da fotografia produz efeito incalculável sobre nossa sensibilidade ética" (SONTAG, 1981, p.23). Fontes iconográficas, embora pareçam "inocentes" em alguns casos, podem ser mais reveladoras que o discurso escrito ou oral, graças às significações que delas podemos extrair, já que são o locus privilegiado para que se desenvolva a observação e a compreensão da dialética que se manifesta entre as realidades materiais e a forma como as olhamos.

Neste sentido, podemos traçar alguns paralelos entre a fotografia tradicional e a fotografia digital. Uma fotografia, no universo analógico, tem uma dimensão física, podendo ser tocada e contemplada sem auxílios externos. O material de que são feitas - prata, corantes, papel, celulóide, gelatina, albúmem, colódio - não é estável. Luz, agentes químicos, umidade e calor afetam e podem até mesmo destruir uma coleção fotográfica. Em muitos casos, o acesso ao documento fotográfico torna-se tecnicamente desaconselhável. As duplicações em filme destas imagens, produzidas com o fim de viabilização do acesso, também não são estáveis, além de duplicarem o volume do acervo. Há de se destacar, no entanto, que esta reformatação convencional, que produz negativos de segunda geração, cópias-contato e ampliações para consulta, continuará sendo importante ferramenta na administração de acervos fotográficos.

Fotografias digitais, por sua vez, não têm um aspecto físico concreto palpável, como o de um negativo em suporte fílmico, por exemplo, sendo constituídas por bits. Para serem contempladas, exigem a utilização de equipamentos complexos. É de grande importância, porém, a rapidez e facilidade com que podem ser copiadas e inseridas em bases de dados com rápido e fácil acesso. Cada cópia poderá ser absolutamente igual a todas as outras, diferentemente do que acontece na fotografia analógica. Poderão ainda ser criados produtos, como os CD-ROMs, DVDs, habilitando museus e arquivos a distribuir suas imagens a um amplo público, ao mesmo tempo que promovem sua preservação. Premissa fundamental: mesmo a melhor cópia digital não substituirá um original, no sentido de seu descarte.

Pouco ou nada se conhece sobre a utilização futura de uma fotografia digitalizada com propósitos arquivísticos. Pouco se sabe acerca das possibilidades tecnológicas que estarão disponíveis dentro de poucos anos. Assim, devese estar atento ao debate em torno das questões críticas

\footnotetext{
* Bit: binary digit $=$ menor medida de informação binária, em que as únicas opções são 'ligado' e 'desligado' (on e off, 'zero' e 'um')
} 
relacionadas à noção de "qualidade de imagem" em versões digitais de acervos fotográficos. É preciso ressaltar que a noção de "alta qualidade" não se define unicamente pelo alto conteúdo informacional dos acervos ou coleções digitais, mas também pela viabilização do acesso e da integridade dos dados ao longo do tempo.

A opção das instituições pelos usuários prioriza efetivamente a liberação de conteúdos informacionais com acesso ampliado para além dos limites da instituição, tornando parte das coleções acessíveis na World Wide Web. No entanto, serão fundamentais, para um tratamento arquivístico, a identificação, a autenticação e a preservação da integridade dos registros disponibilizados na internet. Qualquer ausência ou inadequação no processamento da representação da informação (na sua manutenção) pode provocar a inacessibilidade ao conteúdo. Aprender a selecionar adequadamente as técnicas de produção de cópias é um aspecto essencial no treinamento de arquivistas, bibliotecários e curadores voltados às questões do acesso e da preservação. A opção pelo procedimento adequado deve basear-se na permanência, no custo, no tempo, na qualidade e no uso da cópia pretendida." Além disso, a representação digital da informação traz à tona questões éticas, legais e sociais e ainda as difíceis questões da propriedade intelectual, da proteção da confidencialidade e da privacidade.

A seleção das imagens a ser convertidas constitui este complexo processo de tomada de decisões, que será contínuo. É errôneo imaginar que todas as fotografias de determinada coleção virão a integrar uma base de dados de imagens. $O$ grande número de itens obriga a uma decisão cuidadosa sobre o que digitalizar, baseada em profundo conhecimento acerca da natureza da coleção (e não do conteúdo pictorial das imagens) e no compromisso ético de contemplar as necessidades informacionais do público.

Há trabalhos que apontam diferentes critérios para a seleção, os quais dependerão dos propósitos da digitalização (desenvolvimento de coleções, preservação/ arquivamento ou aperfeiçoamento do acesso). Alguns critérios são aplicados à coleção que será convertida, outros à versão digital. Alguns são critérios convencionais, outros são específicos das tecnologias digitais. Deve-se verificar, por exemplo:

a) se a decisão estará atrelada ao compromisso da instituição com a manutenção da versão digital através

${ }^{*}$ Cf. Silva, 2005. do tempo, considerando-se as mudanças tecnológicas e as ameaças à segurança e baseando-se em uma política que assegure o acesso contínuo aos itens digitalizados que tenham permanente valor para a pesquisa;

b) se a captura digital pode ser adequadamente realizada, sem provocar danos aos originais;

c) se a versão digital será acessível a partir de ambientes de rede e plataformas computacionais institucionais suportadas e em acordo com as normas em uso pela comunidade de bibliotecas e arquivos;

d) se a decisão resolverá problemas técnicos relativos ao acesso aos originais (fragilidade, grandes formatos etc.);

e) se haverá controle das restrições necessárias ao acesso quando determinadas pelo conteúdo dos materiais;

f) se serão providas interfaces de fácil compreensão e utilização para os usuários;

g) se os metadados serão adequadamente providos (identificação, dados de captura, proveniência etc.);

h) se haverá possibilidades de autenticação."

A captura ou digitalização deve ser feita a partir do original, sempre que possível. Esta sempre foi uma questão que gerou muitas polêmicas, várias vezes sem fundamento, entre os profissionais responsáveis pela guarda de originais. Ester (1996) participa da opinião de que a captura deve, idealmente, ser feita a partir do original (seja um original em papel ou em filme) e não a partir de um negativo de segunda geração, já que isto implicaria uma significante perda de qualidade quando comparada a uma digitalização feita a partir do original. Se houver necessidade do uso de intermediários, devese limitar o número de gerações. Não se deve desperdiçar resolução utilizando-se fontes de captura inadequadas ao trabalho que visa ao acesso orientado à preservação. Devemos sempre proceder à captura de alta qualidade, uma vez que usualmente são geradas múltiplas versões derivadas de uma imagem de alta resolução.

Não apenas as questões técnicas são importantes. Há o aspecto cultural que envolve o acesso a acervos fotográficos públicos. Uma versão digital modifica este envolvimento, alterando muito o uso do conteúdo destes acervos e sua própria característica intrínseca de valor simbólico, pois novos tipos de leituras e escritas coletivas tornam-se possíveis.

\footnotetext{
* Limitamos-nos aqui à referência a alguns dos critérios aplicáveis às versões digitais para os propósitos de preservação e acesso. Para a abordagem completa, ver Ogden (1997).
} 
TECNOLOGIA E POLÍTICAS PÚBLICAS NA DISSEMINAÇÃO DE VERSÕES DIGITAIS DE ACERVOS FOTOGRÁFICOS

Indubitavelmente as diferenças entre culturas e processos históricos que caracterizam os povos trazem complexidade ao universo digital. Isso exige a busca de maior clareza e compreensão acerca dos contextos políticos de disseminação de conteúdos digitais mantidos pela esfera pública.

Para González de Gómez, uma "política de informação" constitui-se por "ações e decisões orientadas a preservar, reproduzir ou mudar um regime de informação". Se o regime de informação é o locus do conflito, da diversidade de vontades e efeitos, uma política de informação não se constitui pelos produtos, serviços, recursos e tecnologias resultantes de sua implementação: seu reconhecimento e sua caracterização se darão mediante orientação e direção da vontade dos sujeitos que a agenciam. "É fundamentalmente um ato de desejo, cuja intenção e direção condicionam seus mecanismos de realização" (GONZÁLEZ DE GÓMEZ, 1998, p.3-5).

Com a crescente divisão do trabalho de representação política, do trabalho intelectual, e com a culminação da globalização econômica e eletrônica, promovendo assimetrias na geração e no uso de conteúdos informacionais, passam a ser gerados empecilhos para a transferência desses conteúdos, e apenas alguns dos planos desta transferência passam a ser atendidos, em função de capacidades físicas e econômicas de disponibilidade e acesso a conteúdos, ocorrendo uma transformação dos operadores informacionais, os quais se convertem "em um ambiente multiplicador da informação e da incomunicação" (GONZÁLEZ DE GÓMEZ, 1995, p.82). O fato de hoje colocar-se maior ênfase no fluxo dos conteúdos informacionais do que em seu uso efetivo é freqüentemente explicado pela crença na legitimação da capacidade de as estruturas organizacionais oferecerem condições adequadas para processos de tomadas de decisão nos ambientes altamente competitivos, sem considerar, no entanto, a possibilidade da existência de barreiras na transferência de conteúdos informacionais.

A reformatação digital de acervos fotográficos e sua conseqüente disponibilização para acesso irão, certamente, ao encontro das expectativas de um novo público. É natural que a implementação de sistemas digitais que ofereçam, por meio de novos canais de distribuição, substitutos visuais para as fotografias depositadas em arquivos, museus e bibliotecas, acarrete efeitos significativos à própria coleção e a seu uso. Besser (1996) já comentou que a possibilidade de realizar comparações de imagens mediante aproximações e afastamentos promovidos por efeitos de zoom poderá, por exemplo, conduzir os usuários à descoberta de novas relações existentes entre as imagens, permitindo a participação do usuário comum em atividades que anteriormente eram domínio exclusivo de curadores e outros profissionais especializados. De espectador, o usuário passa a participante.

Dois caminhos são possíveis nesse contexto de mudanças tecnológicas: adquirir uma tecnologia visando à solução de um problema específico (aperfeiçoando, por exemplo, o acesso a conteúdos informacionais), ou adotá-la como uma opção de preservação, sendo necessário, neste caso, um profundo e prolongado compromisso institucional. Qualquer das opções exige entendimento dos propósitos da digitalização que nos habilite a tomar decisões acerca dos parâmetros do processo.

Há a exigência de um esforço enorme para a organização dos grandes estoques de conteúdos informacionais do futuro, de forma a tornar viáveis usos mais adequados. Pode acontecer de aspectos ideológicos do processo informacional se exacerbarem, determinando rumos e governando os âmbitos institucionais. Já se observou que a dicotomia existente em princípios tão arraigados na ideologia profissional vigente dos chamados especialistas da informação - tais como geral/ particular, centralizado/ descentralizado, coordenado/ autônomo, normalizado/ não normalizado, livre acesso/ acesso controlado - será questionada em função de uma mudança de paradigma que transforma conteúdos informacionais em algo abstrato, que independe do suporte, e que exige diferentes abordagens teórico-metodológicas e novas práticas e tecnologias de ciclo de vida e reformatação.

Há, ainda, a necessidade de permanente atenção às questões relacionadas a recursos e fundos para a realização de ajustes institucionais, uma vez que as bibliotecas e arquivos terão de suportar, nesse período de transição e ainda por longo tempo, dois sistemas diferentes, o tradicional e o digital, cujos requisitos conflitantes, despesas e modificações necessárias, poderão de fato ser difíceis de conduzir.

A participação da equipe envolvida nos projetos será fundamental para o sucesso do empreendimento. Para isso, serão necessários investimentos que possibilitem a aquisição de elevado nível de competência técnica e de 
experiência que permitam o desenvolvimento de projetos e a execução das novas iniciativas a serem incorporadas. O treinamento e o crescimento profissional, por si só, já atuam favoravelmente junto aos técnicos como verdadeiro incentivo à participação e, seguramente, constituem parte dos custos da institucionalização da preservação digital, que deverá prever o estabelecimento de novas responsabilidades para os membros da equipe. ${ }^{*}$ Serão necessários novos modelos institucionais de espaços informacionais para o século que se inicia, atentando para o fato de que, no contexto do universo digital, um espaço informacional digital público é também um dispositivo institucional, no sentido de que refletem relações de sociabilidade, comunicação e saber.**

Os governos devem estar atentos às exigências de pesquisa nas diversas áreas associadas ao desenvolvimento de interfaces e à representação da informação, de modo a se habilitarem a atender a necessidades e direitos das novas formas de organização social que já existem nesse novo espaço. É preciso que se desloque a ênfase do objeto, do computador, do programa (aceitando a sugestão de Lévy), para o projeto, para o ambiente cognitivo, para a rede de relações que se pretende estabelecer por meio das interfaces. Os programas atuais e as redes informáticas, "tecnologias intelectuais", ao modificar os circuitos da comunicação e da decisão nas organizações e instituições, reorganizam, de alguma forma, a visão de mundo de seus participantes, modificando seus reflexos mentais.

A especificidade documental dos acervos fotográficos e a convicção acerca da potencialidade da fotografia não só como imagem portadora da possibilidade de um conhecimento, mas também como instrumento para o desenvolvimento da consciência, exigem um modelo de espaço informacional digital que não apenas atenda ao experiente consulente de acervos fotográficos, mas que seja rico em estímulos cognitivos direcionados àqueles que procuram conhecer por meio de imagens do acervo público - aos jovens, sobretudo - e, ainda, que reúna elementos de apoio para o desencadeamento de eventuais processos de cooperação interinstitucional.

\section{CONSIDERAÇÕES FINAIS}

Considerando o grande interesse por imagens fotográficas, deveriam ser idealizados e implementados, em função dos novos contextos tecnológicos institucionais, novos modelos para se reunir, organizar e disponibilizar

\footnotetext{
* Cf. Allen (1998), Kenney e Conway (1998) e Miranda (1996).

*** Cf. González de Gómez, 1998.
}

imagens constituintes do acervo público, de forma que provoquem uma 'mudança no jeito de olhar', visando a inseri-las efetivamente no processo informacional. Organizadas segundo critérios específicos, as imagens apresentar-se-iam como possibilidade de conhecimento, tornando-se importante elemento para o desenvolvimento de uma consciência adquirida pela fruição de séries de representações digitais, disponíveis no ciberespaço.

O resultado da fruição, oriundo de um 'novo olhar', corresponde ao que se poderia chamar de uma expansão da consciência informacional, ou seja, ao fruir as imagens por meio de interfaces mais adequadamente elaboradas, o indivíduo fruidor cuja intenção seja a de conhecer acessa e 'absorve' o conteúdo informacional não apenas como elemento redutor de incerteza, mas como quem se insere em uma dimensão na qual pode ocorrer um processo capaz de expandir a consciência da possibilidade de conhecer e agir em determinado contexto social. A esse processo, essa concatenação de eventos cuja perspectiva é a do conhecimento e da ação, denominamos informação.

É a mudança do olhar, é esse novo olhar que possibilita a reunião de elementos que conduziriam à ampliação da consciência. Para mudar o olhar, é preciso dar às versões digitais das imagens fotográficas, sobretudo as mantidas pela esfera pública, um sentido de organização para o acesso digital que seja capaz de informar, de expandir a consciência, em um processo análogo ao que busca toda arte que se preza.

Artigo submetido em 13/06/2006 e aceito em 13/03/2007.

\section{REFERÊNCIAS}

ALLEN, Nancy. Institutionalizing digitization. Collection Management, v. 22 , n. $3 / 4$, p. $217-223,1998$. Special issue.

BENJAMIN, Walter. A obra de arte na era de sua reprodutibilidade técnica. In: Magia e técnica, arte e politica; Ensaios sobre literatura e história da cultura; Obras Escolhidas. São Paulo: Brasiliense, 1986. v. 1, p. 165-196.

BESSER, Howard. The changing role of photographic collections with the advent of digitization. 1996. Papers. Disponível em: < http:// www.gseis.ucla.edu/ $\sim$ howard/Papers/garmil-eastman.html $>$. Acesso em: 13 jun. 2006.

CANCLINI, Nestor G. Fotografia e ideologia: seus pontos comuns. In: COLÓQUIO LATINO-AMERICANO DE FOTOGRAFIA, 2. 1981, México. Anais... Rio de Janeiro: Ministério da Cultura; México: Conselho Mexicano de Fotografia, 1987. p.13-18.

ESTER, Michael. Digital image collections: issues and practice. Washington, D.C.: Commision on Preservation and Access, 1996. 36 p. 
GONZÁLEZ DE GÓMEZ, Maria Nélida. A informação: dos estoques às redes. Ciência da Informação, Brasília, v. 24, n. 1, p. 77-83, jan./abr. 1995.

. Política de informação em saúde: possibilidades e limites. In: SEMINÁRIO INFORMAÇÕ̃ES EM SAUUDE NO NORDESTE, 1998, Recife, PE. Proposições à formulação de uma política: anais... [S.l.: s.n.], 1998. Cópia fornecida pela autora, impressa a partir de versão digital.

HAERTEL, Nilza G. A magia do silêncio nas artes visuais. Revista Porto Alegre - POA, Porto Alegre, n. 1, p. 56-59, maio 1990.

HOLLANDA, Ricardo de. Fotografia e cidade: a informação nas imagens de Augusto malta e Eugène Atget. In: PINHEIRO, Lena V. R.; GONZÁLEZ DE GÓMEZ, Maria N. (Org.). Interdiscursos da ciência da informação: arte, museu, imagem. Brasília: Ibict, 2000. p.173-182.

KENNEY, Anne; CONWAY, Paul. From analog to digital: extending the preservation tool kit. Collection Management, v. 22, n. 3/4, p. 65-79, 1998. Special issue: Going digital: strategies for access, preservation, and conversion of collections to a digital format.

LEMAGNY, J-C. L'ombre et le temps: essais sur la photographie comme art. Paris: Nathan, 1992. 384 p.

Préface. In: SOULAGES, F. et al. Photographie et inconscient. Paris: Osiris, 1986. p. 5-8.

LEVY, Pierre. As tecnologias da inteligência: o futuro do pensamento na era da informática. Rio de Janeiro: Ed. 34, 1993. 208 p. (Coleção Trans).

MIRANDA, Antonio L. C. Globalización y sistemas de información: nuevos paradigmas e nuevos desafíos. Ciência da Informação, Brasília, v. 25, n. 3, p. 308-313, set./dez. 1996.
OGDEN, Barclay. University of California selection criteria for digitization. 1997. Disponível em: <http://libraries.universityofcalifornia.edu/cdc/ pag/digselec.html>. Acesso em: 13 jun. 2006.

SILVA, Cássia M. Mello. Imagem x palavra: questões da recuperação da informação imagética. In: PINHEIRO, Lena V. R.; GONZÁLEZ DE GÓMEZ, Maria N. (Org.). Interdiscursos da ciência da informação: arte, museu, imagem. Brasília: Ibict, 2000. p. 151-171.

SILVA, Rubens R. G. Digitalização de acervos fotográficos públicos e seus reflexos institucionais e sociais: tecnologia e consciência no universo digital. 2002. Tese (Doutorado em Ciência da Informação)- UFRJ/ ECO; Ibict, Rio de Janeiro, 2002. Disponível em: < http:// biblioteca.ibict.br/phl8/anexos/rubenssilva52002.pdf $>$. Acesso em: 13 jun. 2006.

Por um novo modo de olhar: fotografia, informação e consciência. In: ENANCIB - ENCONTRO NACIONAL DE PESQUISA EM CIÊNCIA DA INFORMAÇÃO, 5., 2003, Belo Horizonte. Informação, conhecimento e transdisciplinaridade: anais... Belo Horizonte: Escola de Ciência da Informação da Universidade Federal de Minas Gerais, 2003. 1 CD-ROM.

Procedimentos básicos de seleção de documentos para conversão digital. In: CINFORM, 6., 2005, Salvador. Informação, conhecimento e sociedade: anais eletrônicos... Salvador: [s.n.], 2005. 1 CD-ROM. Disponível em: < http://www.cinform.ufba.br/vi_anais/docs/ RubensRibeiroSilva.pdf >. Acesso em: 13 jun. 2006.

SONTAG, S. Ensaios sobre a fotografia. Rio de Janeiro: Arbor, 1981.

SOUlAGES, F. et al. Photographie et inconscient. Paris: Osiris, 1986. 